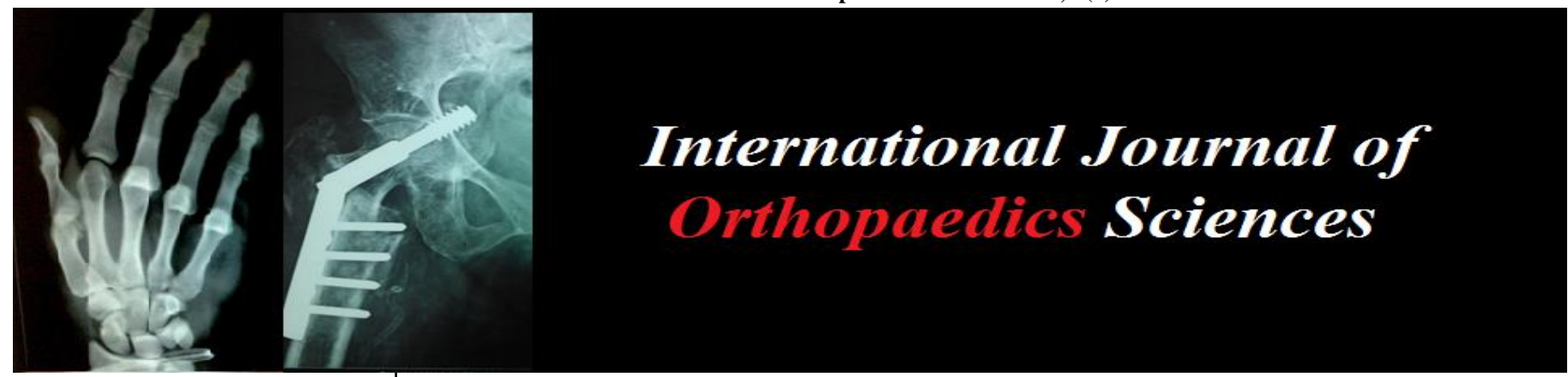

E-ISSN: 2395-1958

P-ISSN: 2706-6630

IJOS 2019; 5(4): 806-808

(C) 2019 IJOS

www.orthopaper.com

Received: 27-08-2019

Accepted: 28-09-2019

Alioune Badara Gueye

Assistant Professor, Department

of Orthopedics, FMPO

Université Cheikh Anta Diop,

Dakar, Senegal

Mouhamadou Niane

UFR Santé, Thies Senegal

Charles Valérie Alain Kinkpé

FMPO Université Cheikh Anta

Diop, Dakar, Senegal

Abdoulaye Ndoye Diop

UFR Santé Université Gaston

Berger, Saint Louis, Senegal

Mohamed Daffé

FMPO Université Cheikh Anta

Diop, Dakar, Senegal

Rokhaya Dia

FMPO Université Cheikh Anta

Diop, Dakar, Senegal

Ndiaye Abdoulaye

FMPO Université Cheikh Anta

Diop, Dakar, Senegal
Corresponding Author: Alioune Badara Gueye Assistant Professor, Department of Orthopedics, FMPO Université Cheikh Anta Diop, Dakar, Senegal

\section{Symptomatic accessory navicular bone: A case report}

\author{
Alioune Badara Gueye, Mouhamadou Niane, Charles Valérie Alain \\ Kinkpé, Abdoulaye Ndoye Diop, Mohamed Daffé, Rokhaya Dia and \\ Ndiaye Abdoulaye
}

DOI: https://doi.org/10.22271/ortho.2019.v5.i4n.1779

\section{Abstract}

Symptomatic accessory navicular bone is a rare condition. The authors report the case of a 30-year-old nurse who had chronic pain in the medial face of her right foot that was resisting to medical treatment. The Radiography revealed the presence of a large accessory navicular bone. Since the treatment was inefficacy, though well conducted, a surgical treatment was administered to the patient which allowed the complete regression of her symptoms. In this case, we will report the diagnostic elements and the different surgical modalities.

Keywords: Accessory navicular bone, foot, pain

\section{Introduction}

The navicular bone on the medial side of the foot is important for normal gait and posture. An accessory navicular bone is present in 4 to $20 \%$ of the population ${ }^{[1,3]}$. Although this is generally an asymptomatic case, an accessory navicular syndrome with internal foot discomfort may occur, particularly in young women ${ }^{[1]}$. This can be caused by trauma or overuse, especially in high-impact sports such as basketball or football. After an ankle trauma in eversion ${ }^{[4,6]}$, it can appear suddenly and then be confused with a fracture ${ }^{[7,8]}$. When it is unknown it may lead to a frequent diagnostic delay of a few months or even years ${ }^{[4,6]}$ causing a delay the initiation of appropriate treatment. The purpose of the work is to recall the diagnostic elements and surgical modalities.

\section{Observation}

A 30-year-old nurse had pain in the medial face of her right foot, which gradually appeared over the past 2 years with minimal trauma. The pain had become more and more frequent and intense, causing disability and lameness.

The clinical examination revealed a small protrusion on the medial surface of the foot. Palpation caused pain in the medial surface compared to the navicular bone, increased by passive eversion and contrarian inversion of the foot. Radiography showed the presence of an accessory navicular bone type II (Figure 1). The ultrasound found a thickened hypoechoic aspect of the distal segment of the posterior leg tendon with a small blade of liquid suggesting partial disinsertion. The CT scan confirmed the presence of an accessory navicular bone (Figure 2).

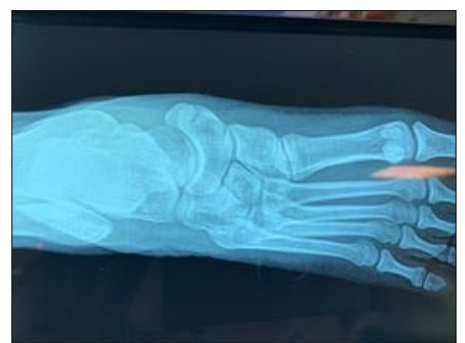

Fig 1: Anteroposterior X-ray shows type II accessory navicular $\sim 806 \sim$ 

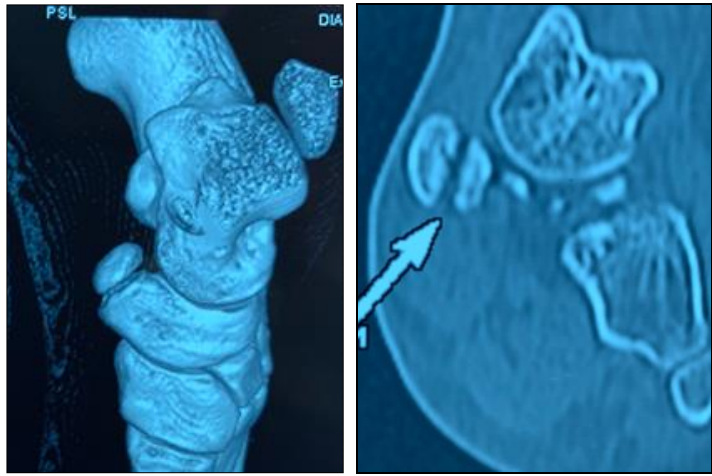

Fig 2: CT scan confirmed the presence of an accessory navicular bone

The patient first received analgesic and anti-inflammatory treatment combined with rest and then an infiltration and partial discharge of the foot. Three months later, as the pain persisted, a surgical operation was performed. The surgical exploration revealed the presence of accessory navicular bone and synchondrosis surrounded by fibrosis, in conflict with posterior tibial tendon insertion, and fibrous synostosis between the medial edge of the talus and accessory navicular bone. The fibers of the posterior legsss tendon were inserted into the accessory navicular. An incision was made in the fibrocartilage between the primary and the accessory navicular after the medial prominence of the primary and accessory navicular was removed by a sagittal saw. Fibrocartilage was removed with an osteotome and a rodent, and the cancellous bone of the primary and accessory navicular vessels was exposed after each surface was flattened and smoothed. The bone accessory to the navicular bone body is screwed in using three Herbert screws (Figures 3). After 12 months of hindsight, the functional result was very satisfactory, with total pain relief and no conflict when wearing shoes.
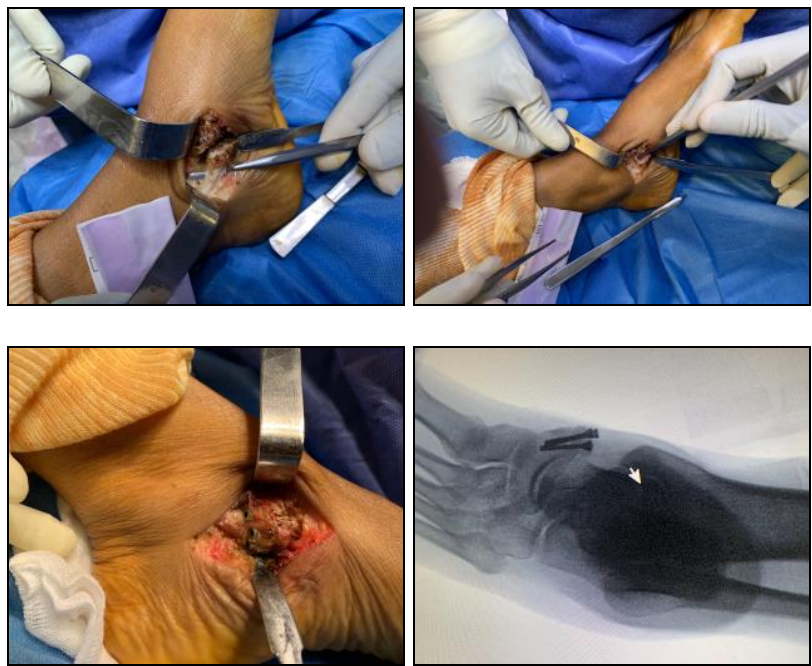

Fig 3: Intraoperative images of accessory navicular bone and control after screwing

\section{Discussion}

The symptomatic accessory navicular tarsal bone mainly causes pain and sensibility along the medial arch of the foot, and an uneasiness when wearing shoes because of the median prominence ${ }^{[1]}$. Pain in the inner foot may then result from micro tears in the tendon or repetitive tensile damage to the inter-navicular joint. It was the case with our patient.

Three types of accessory navicular bone are described and validated by Coughlin $[4,5,7,8]$

- Type I (30\%): small, round or oval bone sesamoid in the thickness of the posterior tibial tendon, located between 3 and $5 \mathrm{~mm}$ from the navicular bone;

- Type II (50\%): triangular, 8 to $12 \mathrm{~mm}$ thick, with a base between 1 and $3 \mathrm{~mm}$ from the navicular bone, which is joined by fibro-cartilage synchondrosis or pseud-arthrosis cartilage;

- $\quad$ Type III (20\%): fusion of sesamoid with the medial tuber of the navicular, giving a prominent navicular tuberosity

In symptomatic forms, treatment with local infiltration of corticosteroids, as well as the administration of analgesics and the wearing of molded plantar orthoses, rarely result in complete pain relief. In this case, the treatment is surgical. Several techniques have been reported in the literature ${ }^{[9,12]}$. For type II some authors recommend in sports subjects, a drilling percutaneous of the synchondrosis in order to induce and accelerate bone consolidation between the navicular bone and its accessory. This technique led to total symptomatic relief in $96.8 \%$ of patients ${ }^{[9,10]}$. Other authors have suggested an ablation of the accessory navicular bone with fixation of the posterior leg if necessary.

An arthrodesis of the navicular bone with its accessory [11]. Scott et al. ${ }^{[12]}$ had evaluated prospectively merging in relation to excision with the advancement of the posterior tibial. In the case of accessory bones of sufficient size, they would screw in. The most described technique, which guided our choice, is inspired by Scott's procedure: a screwing of the navicular bone with its accessory, in case of accessory bone of sufficient size.

\section{Conclusion}

The accessory navicular bone is a rare condition which must be evoked in case of chronic pain in the internal arch. It is medically treated by infiltration and rest. The surgical treatment by screwing also gives satisfactory results.

\section{References}

1. Mukerrin P, McLoughlin R, O’Keffe ST. Accessory navicular syndrome as a cause of foot pain during stroke rehabilitation. Age and ageing. 2018; 0:1-2.

2. Bernaerts A, Vanhoenacker FM, Van de Perre S, De Schepper AM, Parizel PM et al. Accessory navicular bone: not such a normal variant. JBR-BTR. 2004; 87:250-1.

3. Kalbouneh $\mathrm{H}$, Alajoulin $\mathrm{O}$, Alsalem M. Incidence and anatomical variations of accessory navicular bone in patients with foot pain: a retrospective radiographic analysis. Clin Anat. 2017; 3:436-44.

4. Millet-Luft M, Luft A, Alhanati L, Jost D, Tourtier JP. Savoir évoquer le syndrome de l'os accessoire devant une douleur du pied chez un sportif. J Trauma sport. 2017; 34:223-225.

5. Ugolini PA, Raikin SM. The accessory navicular. Foot Ankle Clin. 2004; 9:165-80.

6. Rietveld ABMB, Diemer WM. Surgical treatment of the accessory navicular (os tibiale externum) in dancers: a retrospective case series. J Dance Med Sci. 2016; 20:1038 .

7. Nwawka OK, Hayashi D, Diaz LE, Goud AR, Arndt WF, Roemer FW et al. Sesamoids and accessory ossicles of the foot: anatomical variability and related pathology. Insights Imaging. 2013; 4:581-93.

8. Romanowski CA, Barrington NA. The accessory 
navicular an important cause of medial foot pain. Clin Radiol. 1992; 46:261-4.

9. Bennani A, Benabid M, Leleu JM, Boutayeb F. Os naviculaire tarsien accessoire symptomatique chez le sportif (à propos d'un cas). J Trauma sport. 2012 ; 29:99101.

10. Nakayama S, Sugimoto K, Takakura Y, Tanaka Y. Percutaneous drilling of symptomatic accessory navicular in young athletes. Am J Sports Med 2005;33(4):531-5.

11. Chung JW, Chu IT. Outcome of fusion of a painful accessory navicular to the primary navicular. Foot Ankle Int. 2009; 30(2):106-9.

12. Scott AT, Sabesan VJ, Saluta JR. Fusion versus excision of the symptomatic type II accessory navicular: a prospective study. Foot Ankle Int. 2009; 30:10-5. 